\title{
Prophylaxis of migraine
}

\author{
Ivan Garza \\ Jerry W Swanson \\ Headache Division, Department of \\ Neurology, Mayo Clinic College of \\ Medicine, Mayo Clinic, Rochester, \\ MN, USA
}

\begin{abstract}
Migraine is a common primary headache disorder often associated with significant disability. While many individuals are able to limit therapy to acute treatment of attacks, others need medication to reduce the attack frequency and/or severity. Evidence-based guidelines exist regarding indications and goals for migraine preventive treatment. The specific prophylactic approach needs to be individualized taking into account multiple variables. Medications used in this task vary widely in proven efficacy and presumed mechanisms of action. This review's goal is to discuss the issues that guide the decision-making process in migraine preventive treatment.
\end{abstract}

Keywords: migraine, prevention, prophylaxis

\section{Introduction}

Migraine is a common disabling primary headache disorder. The current International Classification of Headache Disorders provides diagnostic criteria for up to 7 subtypes of migraine (IHSCC 2004). In the US, the prevalence is estimated to be $18.2 \%$ among females and 6.5\% among males 12 years and older (Lipton et al 2001). Although studies in general populations agree that many migraineurs have less than 1 attack per month, in clinical samples the frequency is somewhat higher (Rasmussen and Stewart 2000). Further, the burden of migraine varies, with some individuals experiencing many more attacks and associated disability. A recent study identified 620 active migraineurs from the Netherlands' general population and found that $25 \%$ of them had 2 or more attacks per month (Launer et al 1999). In the US, 35\% of women with migraine experience 1-4 severe attacks a month, and up to $25 \%$ of women experience 4 or more severe attacks a month (Bigal et al 2004). Similar frequency patterns have been observed in men. The economic and public health implications of the significant disability, and the reduced work and school productivity that migraineurs experience can be striking (Lipton et al 2001). Therefore, the emphasis on proper management for the sufferer clearly is of foremost concern. Different types of medications are used in the pharmacologic treatment of migraine and this can be thought of as being acute, preventive, or combined. The optimal therapeutic approach taken varies depending on each clinical scenario.

\section{Brief overview of current management drug strategies}

Migraine prophylaxis should be considered when one or more of the following are present: 1) recurring migraines that significantly interfere with the patient's daily activities, despite acute treatment; 2) frequent headaches; 3) failure, overuse, or contraindication of acute treatments; 4) adverse effects of acute treatment; and/or 5) presence of rare migraine conditions which can potentially cause neurologic damage, such as hemiplegic migraine, basilar migraine, migraine with prolonged aura, or migrainous infarction (USHC 2000).

Whereas some patients will require prophylaxis for only brief periods of time encompassing a predictable triggering situation, most will require long-term treatment. 
Prevention can be viewed as being pre-emptive, short-term "mini-prophylaxis", or chronic (daily medication). A good example of a pre-emptive approach to treatment is the patient who suffers from migraine headaches triggered by sexual activity or by exercise. In these settings, single doses of nonsteroidal anti-inflammatory drugs (NSAIDs) such as indomethacin administered 1 or 2 hours prior to the known triggering activities may be effective (Silberstein et al 2002). Women with pure menstrual migraine in whom, by definition, migraine headaches are restricted to the perimenstrual period in at least 2 out of 3 menstrual cycles (IHSCC 2004), are a good example of an indication for miniprophylaxis. The short-term use of triptans or NSAIDs during the perimenstrual period has shown variable success rates in this subset of patients (Allais et al 2005).

Evidence-based guidelines are available and have stated the following goals for migraine preventive treatment: 1) to reduce attack frequency, severity, and duration; 2) to improve responsiveness to treatment of acute attacks; and 3) to improve function and reduce disability (USHC 2000). Additional goals are to decrease costs of migraine management and perhaps prevent the evolution of episodic to chronic migraine (Silberstein 2005a).

A variety of medications are used for migraine prevention, including beta-adrenergic blockers, antidepressants, anticonvulsants, calcium-channel blockers, serotonin antagonists (cyproheptadine, methysergide), NSAIDs, and others (such as, botulinum toxin, atypical antipsychotics, angiotensin-converting enzyme inhibitors, selective $\mathrm{AT}_{1}$ subtype angiotensin II receptor antagonists). When deciding which drug to use, one has to take into account multiple variables. Ideally, therapy should begin with a drug that has the highest evidence-based efficacy. All comorbid-coexistent conditions (existing simultaneously with and usually independently of migraine) and all medications being taken for these have to be carefully reviewed. Pharmaceuticals that can exacerbate migraine should be identified and discontinued, or changed to a more acceptable alternative if possible. Migraine prophylactics that can adversely affect coexisting disorders and cause unwanted drug interactions should be avoided. Furthermore, if at all feasible, a preventive should be selected that could potentially also treat a coexisting condition, if present. For example, if the migraineur also has hypertension, a betaadrenergic blocker may be a reasonable option to treat both conditions. However, if the migraineur suffers from asthma, a beta-adrenergic blocker could exacerbate it. Patient preference should also be considered. Some prophylactics may either increase or decrease weight and these side-effects may or may not be desired. Women of childbearing age should be on adequate contraception during migraine preventive treatment and migraine prophylaxis with many of the standard agents should be avoided during pregnancy to prevent adverse events and/or teratogenicity related to drugs.

Once a migraine prophylactic has been chosen, therapy should be started at a low dose of the drug to reduce the likelihood of side-effects. The dose should be slowly increased until the desired clinical effect is obtained or until adverse effects interfere. It is possible that the desired clinical benefit is not evident until after 2 or 3 months of using the medication. Therefore, a shorter trial should not be considered a failure until it has been used for at least that amount of time. If significant side-effects occur, it may be necessary to stop the trial. On the other hand, if headaches are well controlled on a migraine prophylactic agent, attempts should be made to taper or even discontinue the medication after 6-12 months of good control. The minimum effective dose is the goal being sought.

\section{Overall effectiveness of current approaches Pre-emptive therapy}

Data are limited on the efficacy of pre-emptive treatment strategies in migraine. Nevertheless, when a known trigger exists, patients can be recommended to use single doses of NSAIDs such as indomethacin prior to the exposure as described above.

\section{Short-term prophylaxis (mini- prophylaxis)}

Migraine attacks occurring in the perimenstrual period have the tendency to be prolonged, intense, and somewhat resistant to analgesics. Therefore, sufferers from pure menstrual migraine or menstrually related migraine are ideal subjects for a short-term migraine prophylaxis. Regular menstrual periods and predictable attacks are imperative (Allais et al 2005). Whereas patients with pure menstrual migraine have attacks only during the perimenstrual period, those with menstrually related migraine have additional attacks at other times of the cycle. Drugs proven to be effective in these settings are NSAIDs, triptans, and dihydroergotamine (DHE) (Silberstein et al 2001). Therapeutic doses of NSAIDs such as naproxen sodium $550 \mathrm{mg}$ twice a day starting 1-2 days before the expected 
onset of headache and continued through the vulnerable period can be effective. Other NSAIDs can be tried instead when the initial choice fails. When gastrointestinal irritation precludes NSAID use, a cyclo-oxygenase (COX)-2 inhibitor such as celecoxib $200 \mathrm{mg}$ once a day is a good alternative when used in the same fashion. A recent abstract suggests celecoxib decreases the number of migraine days, migraine attacks, and other acute medication use in menstrually related migraine (Granella et al 2003).

A study using DHE nasal spray given every 8 hours for 6 days starting 3 days before the headache onset showed a decreased mean pain severity in $67.5 \%$ of 40 patients when compared with placebo (Silberstein et al 2001). Sumatriptan was the first triptan to be investigated for mini-prophylaxis. In an open trial, oral sumatriptan $25 \mathrm{mg} 3$ times a day starting 2-3 days before headache onset and continued for 5 days completely prevented pain in $52.4 \%$ and decreased the headache severity by half or more in $42 \%$ of 126 sumatriptan-treated cycles of menstrually related migraine (Newman et al 1998). Naratriptan $1 \mathrm{mg}$ twice a day for 5 days starting 2 days prior to headache onset gave more headache-free perimenstrual periods, and reduced the number of menstrually associated migraine days when compared with placebo (Newman et al 2001); for reasons that remain unclear, naratriptan $2.5 \mathrm{mg}$ twice daily was not effective for this purpose. More recently, the same strategy was applied to pure menstrual migraine. Naratriptan significantly decreased the mean number of pure menstrual migraine attacks and decreased the severity of headaches (Moschiano et al 2005). Frovatriptan's long half-life and good tolerability profile might make it attractive for shortterm prophylaxis although the significance of triptan's halflife is not entirely understood. At doses of $2.5 \mathrm{mg}$ once or twice a day for 6 days starting 2 days before the headache onset, a reduced attack incidence, duration, severity, and need for rescue medication was seen when compared with placebo (Silberstein, Elkind, et al 2004). It is important to note that women with severe menstrual migraine may respond better to short-term prophylaxis while on a chronic preventive agent.

\section{Chronic prophylaxis}

After extensive evidence-based reviews, the US Headache Consortium provided evidence-based guidelines regarding chronic migraine prophylactic drugs (USHC 2000). The consortium evaluated data available through 1997. Consisting of medications with proven high efficacy and mild to moderate adverse effects, group 1 includes amitriptyline, divalproex sodium, propranolol, and timolol. Drugs with a lower efficacy and mild to moderate adverse effects form group 2, including beta-adrenergic blockers (atenolol, metoprolol, nadolol), calcium-channel blockers (nimodipine, verapamil), NSAIDs (aspirin, fenoprofen, flurbiprofen, ketoprofen, mefenamic acid, naproxen, naproxen sodium), fluoxetine, gabapentin, and others (feverfew, magnesium, vitamin B2). Group 3 involves medications with low to moderate side-effects and safety concerns or complex management issues. This group's efficacy was based on opinion (not randomized clinical trials) and contains antidepressants (bupropion, doxepin, fluvoxamine, imipramine, mirtazepine, nortriptyline, paroxetine, protriptyline, sertraline, trazodone, venlafaxine), others (cyproheptadine, diltiazem, ibuprofen, topiramate), and phenelzine. Methysergide alone comprises group 4, has proven efficacy but also safety concerns or complex management. Finally, composed of drugs proven to have limited or no efficacy at all, group 5 contains carbamazepine, clomipramine, clonazepam, clonidine, indomethacin, nicardipine, nifedipine, and pindolol.

The following section intends to discuss commonly used chronic prophylactics in the authors' adult headache practice (Table 1). Each one is usually tried one at a time as there is scant scientific evidence of combination therapy efficacy and two agents often result in more side-effects than a single agent. Starting doses and range of dosing regimens are followed by recent evidence (since 2000 guidelines), if any available, for the particular medication. All of these are started at a low dose and gradually increased until the minimal tolerable dose that gives benefit is obtained. Sideeffect profiles are briefly touched on.

Amitriptyline is a tricyclic antidepressant usually given orally at bedtime secondary to its sedating effect. The usual starting dose is $10 \mathrm{mg}$ and can be gradually increased by $10 \mathrm{mg}$ per week up to $75 \mathrm{mg}$ or $1 \mathrm{mg} / \mathrm{kg}$ body weight (Lance and Goadsby 2005). It can be particularly useful when comorbid depression, peripheral neuropathy, or insomnia is present. Common side-effects are weight gain, constipation, somnolence, fatigue, and blurred vision in addition to other anticholinergic events. Use with caution if at all in epilepsy, glaucoma, and bipolar disorder. Cardiac dysrhythmias such as tachycardia, changes in atrioventricular (AV) conduction, and heart block are potentially serious side-effects. Concomitant use of monoamine oxidase inhibitors is contra-indicated. When high doses are used, it can be divided in 1-3 doses. 
Table I Commonly used migraine prophylactic medications

\begin{tabular}{|c|c|c|c|c|}
\hline Drug & $\begin{array}{l}\text { Initial dose } \\
(\mathrm{mg})\end{array}$ & $\begin{array}{l}\text { Typical total daily } \\
\text { dose range ( } \mathrm{mg} \text { ) }\end{array}$ & $\begin{array}{l}\text { Common } \\
\text { side-effects }\end{array}$ & $\begin{array}{l}\text { Serious } \\
\text { side-effects }\end{array}$ \\
\hline Amitriptyline & 10 & $25-150$ & Weight gain, constipation, sedation & Cardiac dysrhythmias \\
\hline Nortriptyline & 10 & $25-150$ & Weight gain, constipation, sedation & Cardiac dysrhythmias \\
\hline Divalproex sodium & $250-500$ & $750-1500$ & Alopecia, weight gain, nausea, tremor & $\begin{array}{l}\text { Pancreatitis, liver failure, } \\
\text { thrombocytopenia }\end{array}$ \\
\hline Propranolol & $40-60$ & $40-240$ & Depression, fatigue & Bradyarrhythmia \\
\hline Atenolol & 25 & $50-100$ & Depression, fatigue & Bradyarrhythmia \\
\hline Verapamil & $80-160$ & $160-480$ & Edema, constipation & Hypotension, dysrhythmias \\
\hline Gabapentin & 300 & $900-2400$ & Edema, sedation, fatigue, dizziness & \\
\hline Topiramate & $15-25$ & $75-200$ & Paresthesias, fatigue, weight loss & $\begin{array}{l}\text { Acute angle closure } \\
\text { glaucoma, hyperthermia, } \\
\text { metabolic acidosis, } \\
\text { nephrolithiasis }\end{array}$ \\
\hline
\end{tabular}

Nortriptyline is a tricyclic antidepressant and a major metabolite of amitriptyline. It has a more favorable sideeffect profile and is less sedating when compared with the parent drug. Accordingly, it is frequently prescribed instead of amitriptyline even though the evidence to support its use is much less than that for amitriptyline. The starting dose is $10 \mathrm{mg}$ every night and can be gradually increased up to $150 \mathrm{mg}$ a day if needed (Silberstein et al 2001). Nortriptyline has anticholinergic properties. The side-effects, precautions, and contraindications are similar to those of amitriptyline.

Propranolol is a nonselective beta-adrenergic blocker with a usual starting dose of $40 \mathrm{mg}$ a day. This is gradually increased to a total of $240 \mathrm{mg}$ a day taken in divided doses. A long-acting form is available with a dose range of 60 $160 \mathrm{mg}$ once a day (Mathew 2005). Patients with coexistent hypertension, anxiety, mitral valve prolapse, or benign essential tremor could benefit from its use. Common sideeffects are depression, bradyarrhythmia, fatigue, and exercise intolerance. Myasthenia gravis and diabetes are relative contra-indications. Contra-indications include asthma, congestive heart failure, AV block, and severe sinus bradycardia.

Atenolol is a cardioselective beta-adrenergic blocker with a long half-life and a more favorable side-effect profile compared with propranolol (Silberstein et al 2002). Starting dose is $50 \mathrm{mg}$ a day and is gradually increased up to $100 \mathrm{mg}$ a day (in divided doses) if needed (Mathew 2005). Sideeffect profile, precautions, and contraindications are similar to those of propranolol.

Verapamil is a calcium-channel blocker which could particularly benefit patients with prolonged focal neurologic symptoms, or aura (Mathew 2005). However, no solid evidence exists to support this idea. Nonetheless, verapamil is effective in migraine prophylaxis although the evidence base is limited. The dose range starts at $80 \mathrm{mg}$ a day and is increased as tolerated up to $240 \mathrm{mg}$ a day in divided doses (Toda and Tfelt-Hansen 2000). Common side-effects are hypotension, edema, constipation, dizziness, and nausea. Hypertensive migraineurs can potentially benefit from the hypotensive side-effect. It is contra-indicated in cardiac conduction defects, bradycardia, symptomatic hypotension, and simultaneous beta-adrenergic blocker use.

Divalproex sodium is an antiepileptic. The recommended oral starting dose is $250 \mathrm{mg}$ taken at bedtime and is gradually increased, usually by $125-250 \mathrm{mg}$ per week, to a goal dose of $750 \mathrm{mg}$ per day in 2-3 divided doses (Silberstein 1996). Higher doses may be needed. The extended-release form is efficacious, too (Freitag et al 2002), and could potentially increase compliance since fewer daily doses (once a day) are required. Divalproex's initial benefits can be sustained for prolonged periods of time (Silberstein and Collins 1999). Certain comorbid epilepsy syndromes could benefit from divalproex sodium. Hepatic and/or hematologic dysfunction might occur; therefore, complete blood counts with differential and liver function tests are obtained prior to starting therapy and periodically thereafter. Common sideeffects are alopecia, skin rash, weight gain, nausea, dizziness, somnolence, and tremor. Serious side-effects include pancreatitis, liver failure, and thrombocytopenia. Its use during pregnancy or hepatic disease is contraindicated.

Gabapentin is an anticonvulsant that has been found to be effective in different pain syndromes such as trigeminal neuralgia, postherpetic neuralgia, and diabetic neuropathy. There are two double-blind, placebo controlled-studies available of gabapentin in migraine prophylaxis. The first one used a starting dose of $400 \mathrm{mg}$ a day and was increased by $400 \mathrm{mg}$ every 3 days until a goal dose of $1200 \mathrm{mg}$ a day 
was reached. With this approach, 30 of 63 patients had a significative reduction in migraine frequency and intensity over a 3-month period (Trapani et al 2000). The second study used a starting dose of $300 \mathrm{mg}$ a day and was gradually increased up to $2400 \mathrm{mg}$ a day in divided doses. Gabapentin was superior to placebo in decreasing the median migraine headache rate over a 12-week period (Mathew et al 2001). The drug is generally well tolerated. Common side-effects are peripheral edema, dizziness, somnolence, and fatigue.

Topiramate is another antiepileptic medication used for migraine prophylaxis which now has an FDA-approved indication for migraine prevention. A total dose of $100 \mathrm{mg}$ a day yields similar results to propranolol for reduction in migraine frequency, migraine days, and daily rescue medication use according to a placebo-controlled trial using propranolol as an active control (Diener et al 2004). A double blind, placebo-controlled study obtained significantly decreased mean monthly migraine frequency within the first month of use (Brandes et al 2004). In doses of $100 \mathrm{mg}$ and up to $200 \mathrm{mg}$ a day, another large controlled trial confirmed this finding, with topiramate-treated patients exhibiting a $50 \%$ or more reduction in monthly migraine frequency when compared with placebo (Silberstein, Neto, 2004). The recommended dose starts at $25 \mathrm{mg}$ a day and is gradually increased by $25 \mathrm{mg}$ a week until the total goal dose of $100 \mathrm{mg}$ a day (taken as $50 \mathrm{mg}$ twice a day) is achieved (Brandes 2005). In clinical practice, some patients are able to better tolerate an initial dose of $15 \mathrm{mg}$ and titration in $15 \mathrm{mg}$ increments. Common adverse events are paresthesias, fatigue, anorexia, nausea, and weight loss (Silberstein 2004). Serious side-effects are acute angle-closure glaucoma, hypohydrosis-hyperthermia, metabolic acidosis, and nephrolithiasis. Caution is advised in the setting of cognitive deficits. Based on available data, topiramate is now a firstline agent in migraine prophylaxis and specifically suits patients concerned with weight gain, are overweight, or have concomitant epilepsy (Silberstein 2005b).

\section{Limitations and patient satisfaction \\ Limitations}

\section{Comorbidities, drug interactions, and adverse effects}

Coexistent medical conditions, drug side-effects, and their interactions may preclude some prophylactics from being used in specific cases. A careful review of the patient's history is essential to avoid injurious outcomes. The previous section briefly comments on common and serious adverse effects, precautions, and contraindications of some drugs but is by no means exhaustive.

\section{Medication overuse}

The overuse ( $>15$ times a month) of combination analgesics, opioids, ergot alkaloids, and/or triptans for acute migraine attacks may cause medication overuse headache (Diener et al 2001). Opioids, butalbital-containing combination analgesics, and aspirin-acetaminophen-caffeine have the highest risk for causing this problem, and triptans have moderate risk (Smith et al 2004). The beneficial effect of prophylactics can be abolished during the period of acute symptomatic treatment abuse but can be regained after successful termination of this behavior (Mathew et al 1990). One should identify this problem and limit acute treatment use. Unfortunately, while withdrawing acute analgesics, headaches may worsen. A short course of prednisone starting at $60 \mathrm{mg}$ and tapered down over 6 days may offer some relief during this time (Krymchantowski and Barbosa 2000).

\section{Cost}

Cost varies widely among migraine preventive drugs. Not all patients are able to afford expensive ones. Several strategies may circumvent this problem, including: a) utilizing generic forms if available; b) after titration to the target dose, giving single larger tablets instead of many small ones; c) use of pill splitting (if it does not affect absorption of the drug); and d) using medications that treat comorbid conditions, therefore discarding secondary drugs (Adelman et al 2004). Knowledge of individual pharmaceutical cost is imperative to implement prudent and cost-effective therapeutics.

\section{Oral contraceptives}

The influence of oral contraceptives in migraine is unpredictable. Attacks can start, increase in frequency and severity, improve, or not change at all in the setting of initiating oral contraceptive use (Massiou et al 2000). Approximately a third of women who are adversely affected improve when the hormones are discontinued (Evans et al 2001). Therefore, in some individuals, this may be needed as part of the migraine prevention approach. For example, exogenous estrogen is best avoided in migraine with aura.

\section{Lack of efficacy and tachyphylaxis}

Even after proper trials of different prophylactics, the desired clinical benefit is not always obtained. Moreover, in clinical 
practice, tachyphylaxis can be seen after prolonged use of migraine preventives. Dose adjustments or even a change of drug may be required (Mathew 2005).

\section{Patient satisfaction}

Satisfaction with medical therapeutics has been widely studied in several disciplines. However, this is not the case in migraine, where truly, mediators of patient satisfaction are inadequately understood. Among other factors, satisfaction results from efficacy, effectiveness, ease of use, and adverse events (Davies et al 2000). Each individual's expectations, perceived performance, and/or disappointment are of further weight. Expectations of migraineurs from medications concern their effectiveness, duration of relief, attack recurrence, ease of use, required doses, side-effects, time to go back to normal functioning, and efficacy in relieving associated symptoms (Patrick et al 2003). One needs to consider all these variables while tailoring each patient's treatment plan. Of paramount importance is to convey reasonable expectations since migraine is a chronic condition. With effective prophylaxis, approximately two thirds of patients experience a halving in the number of attacks.

The care of migraineurs does not always need a specialist. Nevertheless, primary care physicians may need to refer the sufferer for headache specialty consultation. A survey of 281 migraineurs showed significantly improved satisfaction, and significantly decreased frequency, duration, and severity of attacks while under headache specialty management (Hu et al 2000).

\section{Opportunities for new prophylactic agents - mechanisms of action, pharmacology, efficacy- tolerability \\ Pathophysiology}

Although a detailed coverage of migraine pathophysiology is beyond the goal of this article, it is fundamental to know a few concepts prior to further discussing possible mechanisms of action of migraine preventives. Migraine is a neurovascular reaction to internal and external environmental changes. The susceptibility for such a reaction is dictated by the balance between inhibition and excitation at different levels of the nervous system, and is influenced by different factors in a given individual (Lance and Goadsby 2005). Albeit partially understood, it is postulated that migraine attack vulnerability is based on neuronal hyperexcitability. An abnormal modulation of brain nociceptive systems further prolongs head pain (Welch 2003). Possibly, specific acute migraine abortive treatments exert their main effect at the peripheral neurovascular system. In contradistinction, preventive medications may act centrally (Lance and Goadsby 2005), and nonspecifically, attempting to suppress hyperexcitability and/or enhance antinociceptive mechanisms (Ramadan 2004). The reason why current prophylactics are effective in migraine is not known although several hypotheses exist (Waeber and Moskowitz 2003).

\section{Possible anti-migraine mechanisms of action of commonly used preventives}

Beta-adrenergic blocking drugs may act on the central catecholaminergic system (Tfelt-Hansen and Rolan 2006). An event-related, slow, negative cerebral potential known as contingent negative variation (CNV), believed to be modulated by this system, tends to normalize after prophylactic therapy with these drugs. Further, there seems to be a significant positive correlation between the potential's amplitude before treatment onset and clinical response, with migraineurs with higher amplitudes benefiting the most (Schoenen et al 1986). Propranolol diminishes central catecholaminergic activity by inhibiting norepinephrine release, reduces neuronal activity and excitability, has membrane-stabilizing properties, and inhibits nitric oxide production (Ramadan 2004). Propranolol is highly lipophilic which gives easy access into the central nervous system (CNS) and therefore has a higher potential for CNS side-effects such as depression (among others) when compared with atenolol. If CNS side-effects preclude or interfere with therapy while on propranolol, a reasonable option is to change to atenolol which is more hydrophilic and poorly gets into the CNS (Tfelt-Hansen and Rolan 2006).

Calcium-channel blockers are a diversified conglomerate of medications, each one acting at different subtypes of channels. They most likely act in migraine through their involvement in CNS neurotransmission (Toda and TfeltHansen 2006). Nitric oxide derived from perivascular nerves has been implicated in originating migraine headaches. Flunarizine decreases calcium influx resulting in decreased activity of neural nitric oxide synthase (Ayajiki et al 1997). Evidence suggests that neurogenic inflammation involving 
the trigeminal-vascular system participates in migraine pathogenesis. A study in rats using alpha-eudesmol, a $\mathrm{P}-\mathrm{Q}$ type calcium-channel blocker, showed vasoactive neuropeptide release inhibition and protection against neurogenic inflammation elicited by trigeminal nerve activation (Asakura et al 2000). Flunarizine is the most effective calcium-channel blocker in migraine but is not available in the US. Verapamil is a good alternative and is well tolerated (Mathew 2005).

The use of antiepileptic drugs for migraine prevention is based on the following concept. Migraine and its associated symptoms may be a result of neuronal hyperexcitability and if this can be suppressed, further migraine attacks can be prevented (Welch 2005). Divalproex sodium is a highly protein-bound fatty acid. Its effect may result from increased brain gamma-aminobutyric acid (GABA) which may attenuate migraine-related events at different levels including the cortex, perivascular parasympathetics or trigeminal nucleus caudalis (TNC); from lowered aspartate levels and N-methyl-d-aspartate (NMDA) receptor activity resulting in attenuated aura related cortical activity or nociceptive transmission through the TNC; and from diminished neurogenic inflammation (Cutrer et al 1997). Topiramate is a D-fructose derivative containing a sulfamate functionality that readily enters the CNS (Silberstein and Tfelt-Hansen 2006). Its anti-migraine properties could result from phosphorylation-mediated inhibition of voltage gated sodium and calcium channels, suppression of glutamate-mediated neurotransmission at the alpha-amino-3-hydroxy-5-methyl-4-isoxazolepropionate (AMPA)-kainate receptor subtype, enhanced GABA type A activity, and calcium channel (subtypes $\mathrm{L}$ and $\mathrm{N}$ ) blockade (Mathew et al 2002; Ramadan 2004). Gabapentin is structurally related to GABA and readily crosses the bloodbrain barrier (Young et al 2004). It enhances GABAmediated inhibition, inhibits GABA metabolism, and modulates L-type calcium channels by binding to its $\alpha_{2} \delta$ subunit (Cutrer 2001). All three anticonvulsants can cause mild to moderate side-effects. They may be first-line preventives when beta-adrenergic blockers or tricyclic antidepressants are contraindicated or when comorbid neurologic and/or psychiatric conditions such as epilepsy or mood disorders are present (Mathew 2001).

Tricyclic antidepressants are lipid-soluble and strongly bind to plasma proteins. Their antihistaminic and antimuscarinic activities are responsible for most of their bothersome adverse effects (Colombo et al 2004). Amitriptyline inhibits norepinephrine and serotonin uptake and is the only antidepressant of this class with established efficacy in migraine prevention. Diffuse noxious inhibition may be enhanced through this mechanism. Other possible mechanisms in migraine could be explained by its ability to block sodium-channels; enhance GABA-mediated inhibition; potentiate endogenous opioids; and intensify descending inhibition on nociceptive pathways (Sawynok et al 2001; Colombo et al 2004; Ramadan 2004). Antimigraine effects seem to be independent of its antidepressant influence (Evers and Mylecharane 2006).

\section{Newer agents}

The efficacy of multiple preventives from the above categories has been established (USHC 2000). Since then, multiple newer drugs have been tried in migraine prophylaxis. Their efficacy remains to be established in most cases and their possible mechanisms of action in migraine remain far from being completely understood.

Botulinum toxin is a potent neurotoxin produced by the anaerobic bacterium Clostridium botulinum and exists as seven distinct serotypes (A-G). It causes muscle relaxation in a dose-dependent fashion at the neuromuscular junction by blocking acetylcholine release and is currently used to treat several conditions associated with raised muscle tone (Ashkenazi and Silberstein 2004). An open-label study using botulinum toxin type A (Botox ${ }^{\circledR}$, Allergan, Inc., Irvine, CA, USA) suggested it as a safe and effective preventive treatment in migraine (Binder et al 2000). Three randomized, double-blind, placebo-controlled studies using Botox for migraine prophylaxis have been performed. The pericranial injection of 25 units (U) significantly reduced migraine frequency, migraine severity, acute medication use, and vomiting over a 3-month period in the first study (Silberstein et al 2000). The following study showed Botox injection in the frontal and temporal regions was effective in reducing pain (Brin et al 2000). Although a trend was seen towards a reduction in migraine frequency and duration, the study lacked appropriate statistical power. More recently, the third study failed to show any efficacy (Evers et al 2004). There is no consistent evidence yet that Botox is effective in migraine prevention (Evers and Mylecharane 2006), although this is an area of very active research. If indeed it helps, its antinociceptive effect likely is not solely explained by its ability to relax muscle. Several theories for analgesic mechanisms have been proposed. Botox may: reduce muscle nociceptor sensitization; act on muscle spindles and their 
supraspinal projections indirectly suppressing muscle pain; decrease neurogenic inflammation; and inhibit substance P release (Ashkenazi and Silberstein 2004). Further, Botox could have anti-migraine properties through inhibition of calcitonin gene-related peptide release from activated trigeminal sensory neurons (Durham et al 2004). In migraine, Botox is typically injected in several pericranial regions using 25-265 $\mathrm{U}$ with common doses approximately 100 or 200 U. If beneficial, treatment may be repeated every 3 months since the effect wears off by that time. Side-effects are usually mild and transient including ptosis, frontal weakness, and local pain at the injection site (Ramadan 2004).

Candesartan is a long-acting angiotensin II receptor blocker with high affinity for the $\mathrm{AT}_{1}$ receptor. A randomized, double-blind, placebo-controlled crossover study done with 60 adult patients suffering 2-6 migraine attacks per month used $16 \mathrm{mg}$ once a day. Over a period of 12 weeks, patients treated with candesartan experienced 13.6 headache days compared with 18.5 in the placebo group. Further, candesartan was favorable in terms of hours with headache, days with migraine, hours with migraine, headache severity index, level of disability, and days of sick leave. No differences were seen in terms of health-related quality of life. The drug tolerability profile was similar to that of placebo (Tronvik et al 2003). Candesartan could exert its anti-migraine properties through a decrease in glutamate release and enhancement of GABA mediated inhibitory tone (Goadsby and Ramadan 2006).

Lisinopril is an angiotensin converting enzyme (ACE) inhibitor. A double-blind, placebo-controlled crossover study done with 60 adult patients suffering 2-6 migraine attacks per month used a starting dose of $10 \mathrm{mg}$ once a day for a week followed by a goal dose of $20 \mathrm{mg}$ once a day. Over a period of 12 weeks, days with migraine were reduced by at least $50 \%$ in 14 of 47 patients that completed data. Hours with headache, days with headache, days with migraine, and headache severity index were significantly reduced with lisinopril compared with placebo (Schrader et al 2001). The drug was well tolerated. Side-effects included dizziness, tendency to faint, and cough. Of particular interest is a recent study suggesting men with the homozygote DD genotype of the ACE gene may be protected against migraine (Lin et al 2005). These men seem to have higher levels of circulating ACE activity.

Zonisamide is a modern anticonvulsant with a long halflife permitting once-a-day dosing. A recent open-label study for refractory migraine used a starting dose of $100 \mathrm{mg}$ a day and was gradually increased to $400 \mathrm{mg}$ a day. Statistically significant improvements were seen by 1 month for headache severity, duration, and frequency and persisted through the 3-month period studied (Drake et al 2004). The drug was well tolerated for the most part with only transient and tolerable side-effects including paresthesias, fatigue, anxiety, weight loss, weight gain, and nausea. However, $11.8 \%$ of patients discontinued the drug secondary to dysphoria and difficulty with concentration.

Multiple other pharmaceuticals including but not limited to those acting on brain energy metabolism such as coenzyme Q10, magnesium, and riboflavin have been tried.

\section{Opportunities for future agents}

The understanding of migraine pathophysiology continues to evolve. While several prophylactics have proven efficacy and multiple others are being actively tried, the mechanisms of action remain speculative. As migraine's pathophysiology and current drug mechanisms including the above described are better understood, newer agents are likely to emerge. One hypothesis is the following. Cortical spreading depression (CSD) is a phenomenon believed to be similar to the human migraine aura. Whether migraine aura indirectly produces pain is still controversial. If it does, drugs that could block this process would potentially be useful and such agents exist (Goadsby and Ramadan 2006).

Currently, acute treatment that targets different receptors mediating the multiple neurochemical reactions leading to individual migraine attacks is a very active area of research. Points of interest in this chain of events besides CSD inhibition include the: inhibiting mechanism of neurovascular coupling neurogenic inflammation; inhibition of nociceptor activation; enhancement of descending modulation; and blocking of peripheral and central sensitization (Ramadan 2005). There is evidence to support that calcitonin gene-related peptide (CGRP) receptor antagonism, adenosine $A_{1}$ receptor agonism, AMPA-kainate antagonism, and vanilloid receptor manipulation could translate into new acute abortive treatments (Goadsby 2004; Sang et al 2004). However, whether such new knowledge could transpose also into the development of new migraine prophylactics is yet to be seen. Opioid receptor-like-1 and arachidonylethanolamide (anandamide) are other receptors that, although less understood at this time, may play a role in future migraine therapy (Goadsby 2004). 


\section{Future management strategies in migraine combining prophylaxis and acute management}

A combined migraine treatment plan that considers avoidance of triggering factors, acute symptomatic treatment, and prophylaxis is indispensable to obtain maximum long-term benefit (D’Amico 2004). While preventives are aimed at containing the incidence and vulnerability to attacks, episodic acute treatment is of paramount importance to reduce migraine-related disability during those episodes. A critical step in the prolonged management of migraineurs is to prevent medication overuse headache, which can render prophylactics ineffective. This is a common problem seen in specialty headache practice. A reasonable rule of thumb to avoid this problem is to limit acute symptomatic treatment such as triptans, among others, to not more than 2 days a week ( 9 days per month) on average. Through a decrease in need for acute treatment, preventives assist in accomplishing this goal.

Other special settings that markedly benefit from combination therapy are those of menstrual migraine and menstrually related migraine. Attacks during this period can be particularly difficult to treat and may not respond to acute analgesics (Allais et al 2005). Women with severe menstrual migraine often respond better to acute treatment while on a chronic prophylactic agent (Silberstein et al 2001). Consequently, combined chronic preventive with a shortterm prophylaxis during the vulnerable period is a logical approach in some of these patients.

The possibility that timely prophylaxis may impede progression to a more chronic and more treatment resistant migraine disorder is currently being entertained (Loder and Biondi 2005). The role of a combined approach in preventing this progression remains to be known. This thought, however, once again accentuates the relevance and importance of migraine prophylaxis.

\section{Conclusions}

Migraine is a common disabling primary headache disorder associated with significant disability. Evidence-based guidelines are available regarding indications and goals for migraine preventive treatment (USHC 2000). The specific prophylactic approach needs to be individualized after multiple variable considerations in order to raise the odds of success and to prevent injurious outcomes. Medications used in this task vary widely in proven efficacy. Their antimigraine mechanisms of action are not entirely understood and remain speculative to this date. Awareness of therapy limitations is crucial to prevent drawbacks in the overall goals established. Migraine's pathophysiology and natural history understanding is evolving. Higher quality medications and preventive approaches should be forthcoming as our knowledge on migraine and the medications we currently use in its treatment increase.

\section{References}

Adelman LC, Adelman JU, Freeman MC, et al. 2004. Pharmacoeconomics: The cost of prophylactic migraine treatments. Headache, 44:1050-5.

Allais G, Bussone G, De Lorenzo C, et al. 2005. Advanced strategies of short-term prophylaxis in menstrual migraine: state of the art and prospects. Neurol Sci, 26: S125-9.

Asakura K, Kanemasa T, Minagawa K, et al. 2000. Alpha-eudesmol, a P/ Q-type $\mathrm{Ca} 2+$ channel blocker, inhibits neurogenic vasodilation and extravasation following electrical stimulation of trigeminal ganglion. Brain Res, 873:94-101.

Ashkenazi A, Silberstein SD. 2004. Botulinum toxin and other new approaches to migraine therapy. Annu Rev Med, 55:505-18.

Ayajiki K, Okamura T, Toda N. 1997. Flunarizine, an anti-migraine agent, impairs nitroxidergic nerve function in cerebral arteries. Eur $J$ Pharmacol, 329:49-53.

Bigal ME, Lipton RB, Stewart WF. 2004. The epidemiology and impact of migraine. Curr Neurol Neurosci Rep, 4:98-104.

Binder WJ, Brin MF, Blitzer A, et al. 2000. Otolaryngol Head Neck Surg, 123:669-76.

Brandes JL. 2005. Practical use of topiramate for migraine prevention. Headache, 45:S66-73.

Brandes, JL, Saper, JR, Diamond M, et al. 2004. Topiramate for migraine prevention, a randomized controlled trial. JAMA, 291:965-73.

Brin MF, Swope DM, O’Brien C, et al. 2000. Botox for migraine: doubleblind, placebo-controlled, region-specific evaluation [abstract]. Cephalalgia, 20:421-2(Abstract 386).

Colombo B, Annovazzi POL, Comi G. 2004. Therapy of primary headaches: the role of antidepressants. Neurol Sci, 25:S171-5.

Cutrer FM. 2001. Antiepileptic drugs: how they work in headache. Headache, 41:S3-10.

Cutrer FM, Limmroth V, Moskowitz MA. 1997. Possible mechanisms of valproate in migraine prophylaxis. Cephalalgia, 17:93-100.

D’Amico D. 2004. Treatment strategies in migraine patients. Neurol Sci, 25:S242-3.

Davies GM, Santanello N, Lipton R. 2000. Determinants of patient satisfaction with migraine therapy. Cephalalgia, 20:554-60.

Diener H, Katasarva Z. 2001. Analgesic/abortive overuse and misuse in chronic daily headache. Curr Pain and Headache Rep, 5:545-50.

Diener H, Tfelt-Hansen P, Dahlof C, et al. 2004. Topiramate in migraine prophylaxis, Results from placebo-controlled trial with propranolol as an active control. J Neurol, 251:943-50.

Drake ME, Greathouse NI, Renner JB, et al. 2004. Open-label zonisamide for refractory migraine. Clin Neuropharmacol, 27:278-80.

Durham PL, Cady R, Cady R. 2004. Regulation of calcitonin gene-related peptide secretion from trigeminal nerve cells by botulinum toxin type a: implications for migraine therapy. Headache, 44:35-43.

Evans RW, Lipton RB. 2001. Topics in migraine management, a survey of headache specialists highlights some controversies. Neurol Clin, 19:121.

Evers S, Mylecharane EJ. 2006. Nonsteroidal anti-inflammatory and miscellaneous drugs in migraine prophylaxis. In Olesen $\mathrm{J}$ (ed). The headaches. 3rd ed. Philadelphia, PA, USA: Lippincott Williams and Wilkins. p 553-66. 
Evers S. Vollmer-Haase J, Schwaag S, et al. 2004. Botulinum toxin A in the prophylactic treatment of migraine-a randomized, double-blind, placebo-controlled study. Cephalalgia, 24:838-43.

Freitag FG, Collins SD, Carlson HA, et al. 2002. A randomized trial of divalproex sodium extended-release tablets in migraine prophylaxis. Neurology, 58:1652-9.

Goadsby PJ. 2004. Post-triptan era for the treatment of acute migraine. Curr Pain and Headache Rep, 8:393-8.

Goadsby PJ, Ramadan NH. 2006. Potential new drugs for acute and prophylactic treatment of migraines. In Olesen $\mathrm{J}$ (ed). The headaches. 3rd ed. Philadelphia, PA, USA: Lippincott Williams and Wilkins. p 569-76.

Granella F, Allais G, Benedetto C. 2003. Cyclo-oxygenase-2 inhibitors as short-term prophylaxis of menstrually related migraine. A pilot study [abstract]. Cephalalgia, 23:731.

Hu XH, O’Donnell F, Kunkel RS, et al. 2000. Survey of migraineurs referred to headache specialists: Care, satisfaction, and outcomes. Neurology, 55:141-3.

[IHSCC] International Headache Society Classification Committee. 2004. International classification of headache disorders, 2nd ed. Cephalalgia, 24(Suppl 1): 25.

Krymchantowski AV, Barbosa JS. 2000. Prednisone as initial treatment of analgesic-induced daily headache. Cephalalgia, 20:107-13.

Lance JW, Goadsby PJ. 2005. Migraine: treatment. In Lance JW (ed). Mechanism and management of headache. 7th ed. Philadelphia, PA: Elsevier Butterworth Heinemann. p 123-62.

Launer LJ, Terwindt GM, Ferrari MD. 1999. The prevalence and characteristics of migraine in a population-based cohort: The GEM Study. Neurology, 53: 537-42.

Lin J, Wang P, Chen C, et al. 2005. Homozygous deletion genotype of angiotensin converting enzyme confers protection agains migraine in man. Acta Neurol Taiwan, 14:120-5.

Lipton RB, Stewart WF, Diamond S, et al. 2001. Prevalence and burden of migraine in the United States: data from the American Migraine Study II. Headache, 41:646-57.

Loder E, Biondi D. 2005. General principles of migraine management: the changing role of prevention. Headache, 45:S33-47.

Massiou H, MacGregor EA. 2000. Evolution and treatment of migraine with oral contraceptives. Cephalalgia, 20:170-4.

Mathew NT. 2001. Antiepileptic drugs in migraine prevention. Headache, 41:S18-24.

Mathew NT. 2005. Preventive treatment of migraine. In Evans RW (ed). Handbook of headache. 2nd ed. Philadelphia, PA: Lippincott Williams and Wilkins. p 88-112.

Mathew NT, Kailasam J, Meadors L. 2002. Prophylaxis of migraine, and cluster headache with topiramate. Headache, 42:796-803.

Mathew NT, Kurman R, Perez F. 1990. Drug induced refractory headache - clinical features and management. Headache, 30:634-8.

Mathew NT, Rapoport A, Saper J, et al. 2001. Efficacy of gabapentin in migraine prophylaxis. Headache, 41:119-28.

Moschiano F, Allais G, Grazzi L, et al. 2005. Naratriptan in the short-term prophylaxis of pure menstrual migraine. Neurol Sci, 26:S162-6.

Newman LC, Lipton RB, Lay CL, et al. 1998. A pilot study of oral sumatriptan as intermittent prophylaxis of menstruation-related migraine. Neurology, 51:307-9.

Newman L, Mannix LK, Landy S, et al. 2001. Naratriptan as short-term prophylaxis of menstrually associated migraine: a randomized, doubleblind, placebo-controlled study. Headache, 41:248-56.

Patrick DL, Martin ML, Bushnell DM, et al. 2003. Measuring satisfaction with migraine treatment: expectations, importance, outcomes, and global ratings. Clin Ther, 25:2920-35.

Ramadan NM. 2004. Prophylactic migraine therapy: mechanisms and evidence. Curr Pain and Headache Rep, 8:91-5.

Ramadan NM. 2005. Targeting therapy for migraine, what to treat? Neurology, 64(Suppl 2):S4-8.
Rasmussen BK, Stewart WF. 2000. Epidemiology of migraine. In Olesen J (ed). The headaches. 2nd ed. Philadelphia, PA, USA: Lippincott Williams and Wilkins. p 230.

Sang CN, Ramadan NM, Wallihan RG, et al. 2004. LY293558, a novel AMPA/GluR5 antagonist, is efficacious and well-tolerated in acute migraine. Cephalalgia, 24:596-602.

Sawynok J, Esser MJ, Reid AR. 2001. Antidepressants as analgesics: an overview of central and peripheral mechanisms of action. J Psychiatry Neurosci, 26:21-9.

Schoenen J, Maertens de Noordhout A, et al. 1986. Contingent negative variation and efficacy of beta-blocking agents in migraine. Cephalalgia, 6:229-33.

Schrader H, Stovner LJ, Helde G, et al. 2001. Prophylactic treatment of migraine with angiotensin converting enzyme inhibitor (lisinopril): randomised, placebo controlled, crossover study. BMJ, 322:1-5.

Silberstein SD. 1996. Divalproex sodium in headache: literature review and clinical guidelines. Headache, 36:547-55.

Silberstein SD. 2004. Topiramate in migraine prevention: evidence-based medicine from clinical trials. Neurol Sci, 24:S244-5.

Silberstein SD. 2005a. Preventive treatment of headaches. Curr Opin Neurol, 18: 289-92.

Silbertstein SD. 2005b. Topiramate in migraine prevention. Headache, 45:S57-65.

Silberstein SD, Collins SD. 1999. Safety of divalproex sodium in migraine prophylaxis: an open-label, long-term study. Headache, 39:633-43.

Silberstein SD, Elkind AH, Schreiber C, et al. 2004. A randomized trial of frovatriptan for the intermittent prevention of menstrual migraine. Neurology, 63:261-9.

Silberstein SD, Lipton RB, Goadsby PJ. 2002. Migraine: diagnosis and treatment. In Silberstein SD (ed). Headache in Clinical Practice. 2nd ed. London, UK: Martin Dunitz Ltd. p 69-111.

Silberstein S, Mathew N, Saper J, et al. 2000. Botulinum toxin type A as a migraine preventive treatment. Headache, 40:445-50.

Silberstein SD, Neto W, Schmitt J, at al. 2004. Topiramate in migraine prevention, results of a large controlled trial. Arch Neurol, 61:490-5.

Silberstein SD, Saper JR, Freitag FG. 2001. Migraine: diagnosis and treatment. In Silberstein SD (ed). Wolff's headache and other head pain. 7th ed. New York: Oxford University Pr. p 121-237.

Silberstein SD, Tfelt-Hansen P. 2006. Antiepileptic drugs in migraine prophylaxis. In Olesen J (ed). The headaches. 3rd ed. Philadelphia, PA, USA: Lippincott Williams and Wilkins. p 539-44.

Smith TR, Stoneman J. 2004. Medication overuse headache from antimigraine therapy, clinical features, pathogenesis and management. Drugs, 64:2503-14.

Tfelt-Hansen P, Rolan P. 2006. B-adrenoceptor blocking drugs in migraine prophylaxis. In Olesen J (ed). The headaches. 3rd ed. Philadelphia, PA, USA: Lippincott Williams and Wilkins. p 519-28.

Toda N, Tfelt-Hansen, P. 2000. Calcium antagonists in migraine prophylaxis. In Olesen J (ed). The headaches. 2nd ed. Philadelphia, PA, USA: Lippincott Williams and Wilkins. p 477-82.

Toda N, Tfelt-Hansen P. 2006. Calcium antagonists in migraine prophylaxis. In Olesen J (ed). The headaches. 3rd ed. Philadelphia, PA, USA: Lippincott Williams and Wilkins. p 539-44.

Trapani GD, Mei D, Mazza S, et al. 2000. Gabapentin in the prophylaxis of migraine: a double-blind randomized placebo-controlled study. Clin Ther, 151:145-8.

Tronvik W, Stovner LJ, Helde G, et al. 2003. Prophylactic treatment of migraine with an angiotensin II receptor blocker. JAMA, 289:65-9.

[USHC] United States Headache Consortium. 2000. Practice parameter: evidence-based guidelines for migraine headache (an evidence-based review), Report of the Quality Standards Subcommittee of the American Academy of Neurology. American Academy of Neurology, p 1-11.

Waeber C, Moskowitz MA. 2003. Therapeutic implications of central and peripheral neurologic mechanisms in migraine. Neurology, 61:S920. 
Welch KMA. 2003. Contemporary concepts of migraine pathogenesis. Neurology, 61:S2-8.

Welch KM. 2005. Brain hyperexcitability: the basis for antiepileptic drugs in migraine prevention. Headache, 45:S25-32.

Young WB, Siow HC, Silberstein SD. 2004. Anticonvulsants in migraine. Curr Pain and Headache Rep, 8:244-50. 
